\title{
Acute B Hepatitis after Hepatitis C Virus Therapy with Direct Acting Antivirals in a Co-infected Patient with HIV
}

María Paniagua García*, Inmaculada López Hernández, Felipe Fernández Cuenca and María José Rios Villegas

Unit Clinical Management of Infectious Diseases, Microbiology and Preventive Medicine, Virgen Macarena University Hospital and Virgen del Rocio-IBiS, Sevilla, Spain

*Corresponding author: María Paniagua García, Unit Clinical Management of Infectious Diseases, Microbiology and Preventive Medicine, Virgen Macarena University Hospital and Virgen del Rocio-IBiS, Sevilla, Spain, Tel: +34 955008 286; E-mail: maria.paniagua89@gmail.com

Recieved date: September 20, 2016; Accepted date: October 25, 2016; Published date: November 1, 2016

Copyright: @ 2016 Garcia MP et al. This is an open-access article distributed under the terms of the Creative Commons Attribution License, which permits unrestricted use, distribution, and reproduction in any medium, provided the original author and source are credited.

\section{Abstract}

Up until now, few cases of HBV reactivation after HCV therapy with new direct acting antivirals have been communicated, the majority of them without clinical repercussion. We present a case of fulminant hepatic failure for HBV reactivation in a patient infected with human immunodeficiency virus, after HCV therapy with DAAs.

Keywords: Hepatitis C virus; Hepatitis B virus reactivation; Human immunodeficiency virus; Direct acting antivirals

\section{Introduction}

Hepatitis $\mathrm{C}$ virus (HCV) infection is one of the major causes of chronic hepatic disease, generating a variable long-term impact, from minimal histological changes to advanced fibrosis, with or without hepatocellular carcinoma [1]. Globally, there are approximately 160 millions people chronically infected with HCV. The introduction of direct acting antivirals (DAAs) has meant an improvement in HCV management, both in naïve and previously treated without success patients. These are oral drugs that directly inhibit the HCV replication cycle, and they lead to higher sustained virological response compared with interferon-based regimens, with a shorter duration and less adverse events.

Frequently, HCV patients are co-infected with hepatitis B virus (HBV) and/or human immunodeficiency virus (HIV), which increase the risk of progression into cirrhosis and hepatic decompensation. It has been estimated [2] that 400 millions people are HBV carriers globally, $75 \%$ of whom are from Asia and West Pacific.

Within HIV patients, approximately [3] 25\% are also infected with HCV, with higher rates (approximately 75\%) among parenteral drugs users and infected through transfusion. $10 \%$ of HIV patients are coinfected with $\mathrm{HBV}$, with high differences between regions. However, due to the lack of big scale population studies, the exact number of patients co-infected HCV-HBV and HCV-HBV-HIV is unknown.

In $\mathrm{HCV}$ and $\mathrm{HBV}$ co-infected patients, $\mathrm{HCV}$ elevated viral load usually is associated with low HBV levels [4], independently of HIV infection. HVB reactivation is a well-known process in the context of immunosuppression [5], and there have been communicated punctual increases of HBV DNA after treatment with pegylated interferon and ribavirin, without any clinical repercussion, where it seems that interferon is active against both viruses.
In this context we present a case of HBV reactivation after $\mathrm{HCV}$ treatment with DAAs (Ledipasvir/Sofosbuvir), in a patient with a past HBV infection, chronic HCV infection genotype la and HIV infection.

\section{Case Report}

The case we show is a 53 years-old patient, smoker, former parenteral drug user and with history of arterial hypertension, chronic pulmonary obstructive disease GOLD (Global Initiative for Obstructive Lung Diseases) IV and peripheral artery disease. The patient was diagnosed of HIV in 1998 after being diagnosed of a pulmonary tuberculosis and possible Pneumocystis jirovecii pneumonia, with an adequate response to antiretroviral treatment. He also had a chronic HCV infection genotype 1a and a history of a past HBV infection with positive core IgG antibody (anti-HBc IgG), both surface antigen (HBsAg) and antibody ( $\mathrm{HBsAb}$ ) negatives, with undetectable DNA-HBV, prior to DAA treatment.

Regarding HIV infection, the patient has followed different therapeutic schedules (Figure 1) with plenty of failure and resistance development, and a remarkable resistance to Zidovudine and Lamivudine, Nevirapine hepatotoxicity and intolerance to Efavirenz. In October 2011 treatment with Tenofovir (TDF), Abacavir and Atazanavir/Ritonavir was started, but later, due to worsening in renal function, TDF was removed and treatment was simplified to Darunavir/Cobicistat, with an excellent adhesion and response, undetectable viral load and $\mathrm{T}$ CD4 lymphocytes between $500-800 / \mathrm{mm}^{3}$ since then $\left(800 / \mathrm{mm}^{3} \mathrm{CD} 4\right.$ lymphocytes in last control, before HCV treatment with DAAs).

In October $2013 \mathrm{HCV}$ treatment was started, following the schedule pegylated interferon (PEG-IFN) alpha-2a, $180 \mathrm{mcg}$, one injection weekly, and Ribavirin $1000 \mathrm{mg}$ daily (3-0-2), reaching a HCV viral load fall of 3 logarithms in week 4 of treatment. In that moment we considered adding first generation direct antivirals (Telaprevir), but the patient had bad tolerance to PEG-IFN and refused to continue with treatment. 


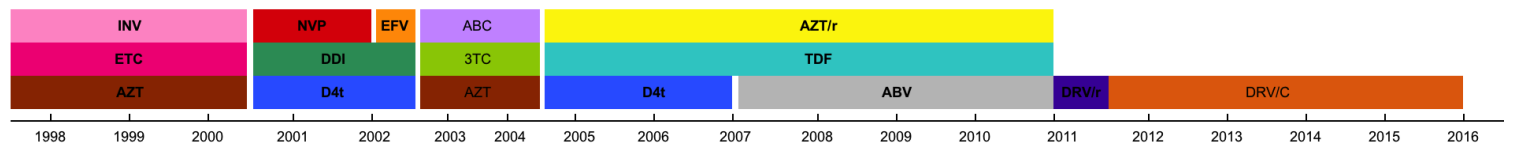

Figure 1: Antiretroviral therapy (ART) followed since HIV diagnosis.

In December 2015 the patient had a HCV viral load of 2,181,330.11 $\mathrm{UI} / \mathrm{mL}$, with a hepatic elastometry of $12 \mathrm{Kpa}$, so we decided to start treatment with DAAs: Sofosbuvir and Ledipasvir during 12 weeks. In week 2 of treatment the viral load had descended to $284.51 \mathrm{Ul} / \mathrm{ml}$, $30.45 \mathrm{UI} / \mathrm{ml}$ in week 4 , and less of $15 \mathrm{UI} / \mathrm{ml}$ from week 8, reaching sustained viral response at week 4 post treatment.

A month later, the patient consulted for abdominal pain, nausea and marked jaundice, with a total bilirubin of $10.98 \mathrm{mg} / \mathrm{dl}$, direct bilirubin of $8,75 \mathrm{mg} / \mathrm{dl}$, glutamic-oxalacetic transaminase (GOT) of 1025.40 $\mathrm{UI} / \mathrm{L}$, glutamate-pyruvate transaminase (GPT) of $642 \mathrm{UI} / \mathrm{L}$ with International Normalized Ratio (INR) of 1.30. HBV viral load was 6, 193, $455.96 \mathrm{UI} / \mathrm{ml}$, with a serologic pattern of positive HBsAg, anti$\mathrm{HBc}$ IgM and HBeAg. HCV viral load was still undetectable, and hepatic D virus was negative. Therefore we were facing an acute B hepatitis.

Treatment with Entecavir against HBV was initiated (TDF had previously been suspended for renal function worsening), however clinical evolution was unfavourable, with ascites, encephalopathy and INR and transaminases increase, so the patient was included into hepatic transplantation study. In spite of treatment the patient was still worsening and he was transferred to Intensive Care Unit, were he continued with a bad clinical evolution and died due to acute hepatic failure.

As we were facing a case of acute hepatitis in the context of HBV reactivation after DAA treatment in a co-infected HCV and HBV patient, we requested HBV viral load from the samples collected during HCV treatment. This way we obtained an undetectable HBV viral load at the beginning of the treatment and at week 2, but that was progressively increasing to $98.80 \mathrm{UI} / \mathrm{mL}$ at week 8 of treatment and to $82,700 \mathrm{UI} / \mathrm{mL}$ at week 4 -post treatment (Figure 2).

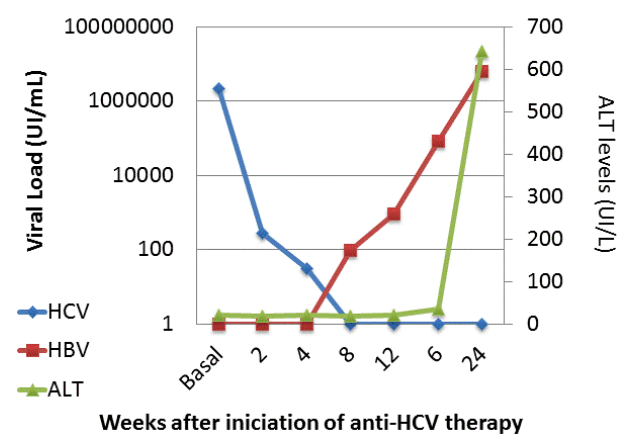

Figure 2: HCV and HBV viral load after HCV therapy, ALT levels.

The risk of HBV reactivation in the context of immunosuppressive therapy (chemotherapy, biological treatment -specially Rituximab and
AntiTNF-, solid organ transplantation) is well known [5] and this supposes a serious complication. In these cases it is recommended to systematically determine $\mathrm{HBsAg}$ and anti- $\mathrm{HBc}$ and to start an adequate antiviral treatment in positive $\mathrm{HBsAg}$ patients and positive anti-HBc with negative HBsAg patients, due to the risk of seroconversion in these cases.

However, some cases of $\mathrm{HBV}$ reactivation in the context of treatment with DAAs in co-infected $\mathrm{HCV}$ an $\mathrm{HBV}$ are being communicated [6-8], the majority of them are asymptomatic and with no clinical repercussion, with a good response to nucleoside/nucleotide analogues, except for one 59 years old patient [9] genotype 1b, with a positive anti-HBc and undetectable $\mathrm{HBV}$ DNA prior to $\mathrm{HCV}$ treatment with DAAs (Simeprevir, Sofosbuvir and Ribavirin), who developed at week 11 of treatment a fulminant acute hepatitis that required hepatic transplantation.

Also, in a recent study [10] with a low number of patients to evaluate the efficacy of treatment with Sofosbuvir and Ledipasvir 12 weeks in coinfected HBV and HCV genotype 1 patients, DNA HBV increments of $88 \%$ were notified, none of them higher than 20.000 $\mathrm{UI} / \mathrm{mL}$, and with no association to neither acute hepatitis and need of treatment.

Usually, in co-infected HCV and HBV patients, HBV DNA is low or undetectable [4], but it can fluctuate, and HCV is the principal cause of chronicle hepatic activity. Different theories [11] to explain HBV replication inhibition in co-infected patients had been proposed. The first of them is that there seems to be a direct interaction between both viruses, so $\mathrm{HCV}$ inhibits $\mathrm{HBV}$ replication, and that inhibition disappears when HCV is treated. Also it has been proposed that after HCV treatment there is more space available for HBV replication. The most accepted theory for the moment is that HCV replication makes a favourable immune situation in the organism, which is able to control HBV replication, and this situation is interrupted with DAAs treatment.

So, since the introduction of DAAs in 2014 and the big scale treatment of $\mathrm{HCV}$ patients, some isolated cases of $\mathrm{HBV}$ reactivation have being communicated, both in co-infected patients or with isolated anti-HBc, independently to the type of infection, which makes us consider the security of these therapies in co-infected HCV, HBV and HIV patients, as they seem to have no activity against HBV [12].

\section{Conclusion}

This is the first case described in literature of fulminant HBV reactivation leading to fulminant hepatic failure after HCV therapy with DAAs in a patient co-infected with HIV. It is unknown if the fact of having HIV infection has any relationship with reactivation or with the bad clinical evolution. Also, we need to take into account that a considerable number of co-infected $\mathrm{HCV}$ and HIV patients are 
Citation: García MP, Hernández IL, Cuenca FF, Villegas MJR (2016) Acute B Hepatitis after Hepatitis C Virus Therapy with Direct Acting Antivirals in a Co-infected Patient with HIV. J Liver 5: 203. doi:10.4172/2167-0889.1000203

Page 3 of 3

following nucleoside/nucleotide analogues treatment, which could prevent $\mathrm{HBV}$ reactivation after DAAs therapy.

\section{References}

1. European Association for Study of Liver (2015) EASL Recommendations on Treatment of Hepatitis C 2015. J Hepatol 63: 199-236.

2. Konstantinou D, Deutsch M (2015) The spectrum of $\mathrm{HBV} / \mathrm{HCV}$ coinfection: epidemiology, clinical characteristics, viral interactions and management. Ann Gastroenterol 28: 221-228.

3. Soriano V, Vispo E, Labarga P, Medrano J, Barreiro P (2010) Viral hepatitis and HIV co-infection. Antiviral Res 85: 303-315.

4. Wiegand SB, Jaroszewicz J, Potthoff A, Zu H, Siederdissen C, et al. (2015) Dominance of hepatitis $\mathrm{C}$ virus $(\mathrm{HCV})$ is associated with lower quantitative hepatitis $\mathrm{B}$ surface antigen and higher serum interferon-?induced protein 10 levels in $\mathrm{HBV} / \mathrm{HCV}$-coinfected patients. Clin Microbiol Infect 21: 710e-710e9.

5. Di Bisceglie AM, Lok AS, Martin P, Terrault N, Perrillo RP, et al. (2015) Recent US Food and Drug Administration warnings on hepatitis B reactivation with immune-suppressing and anticancer drugs: just the tip of the iceberg? Hepatology 61: 703-711.

6. Collins JM, Raphael KL, Terry C, Cartwright EJ, Pillai A, et al. (2015) Hepatitis B Virus Reactivation During Successful Treatment of Hepatitis C Virus With Sofosbuvir and Simeprevir. Clin Infect Dis 61: 1304-1306.
7. De Monte A, Courjon J, Anty R, Cua E, Naqvi A, et al. (2016) Directacting antiviral treatment in adults infected with hepatitis $\mathrm{C}$ virus: Reactivation of hepatitis B virus coinfection as a further challenge. J Clin Virol 78: 27-30.

8. Takayama H, Sato T, Ikeda F, Fujiki S (2016) Reactivation of hepatitis B virus during interferon-free therapy with daclatasvir and asunaprevir in patient with hepatitis B virus/hepatitis C virus co-infection. Hepatol Res 46: 489-491.

9. Ende AR, Kim NH, Yeh MM, Harper J, Landis CS (2015) Fulminant hepatitis $\mathrm{B}$ reactivation leading to liver transplantation in a patient with chronic hepatitis $\mathrm{C}$ treated with simeprevir and sofosbuvir: a case report. J Med Case Rep 9: 164.

10. Gane EJ, Hyland RH, An D, Svarovskaia ES, Brainard D, et al. (2016) Ledipasvir and sofosbuvir for HCV infection in patients coinfected with HBV. Antivir Ther.

11. Balagopal A, Thio CL (2015) Editorial Commentary: Another Call to Cure Hepatitis B. Clin Infect Dis 61: 1307-1309.

12. Liu CJ (2014) Treatment of patients with dual hepatitis $C$ virus and hepatitis B virus infection: resolved and unresolved issues. J Gastroenterol Hepatol 29: 26-30. 